Araştırma Makalesi / Research Paper

\title{
Rosmarinus officinalis Uçucu Yağı ile Verbascum cheiranthifolium ve Chry- santhemum cinerariaefolium Ekstraktlarının Sera Beyaz Sineği (Trialeurodes vaporariorum)'ne Etkileri
}

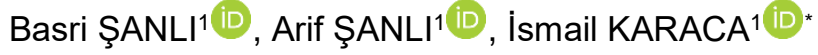 \\ ${ }^{1}$ Isparta Uygulamalı Bilimler Üniversitesi, Tarım Bilimleri ve Teknolojileri Fakültesi, Isparta \\ Geliş Tarihi (Received): 24.09.2019, Kabul Tarihi (Accepted): 09.03.2020 \\ $\square$ Sorumlu Yazar (Corresponding author ${ }^{*}$ ): ismailkaraca@isparta.edu.tr \\ (C) +902462118141 且 +902462114885
}

\section{ÖZ}

Bu çalışmada, sığırkuyruğu (Verbascum cheiranthifolium) ve krizantem (Chrysanthemum cinerariaefolium) ekstraktları ile biberiye (Rosmarinus officinalis) uçucu yağının domates (Lycopersicon esculentum) bitkisinde önemli zarara neden olan sera beyaz sineği (Trialeurodes vaporariorum)'ne karşı etkileri araştırılmıştır. Çalışmada 5 farklı konsantrasyonda hazırlanan bitki ekstraktları ve uçucu yağ, domates bitkilerine daldırma ve püskürtme olmak üzere iki değişik yöntemle uygulanmıştır. Uygulamadan 24 saat sonra yapılan sayımlarda en yüksek ölüm oranı $\% 46,3$ oranla biberiye uçucu yağı uygulamasında gözlenirken, sığırkuyruğu ve krizantem uygulamalarında etki belirlenmemiştir. Uygulamadan 72 saat sonra yapılan sayımlarda ölüm oranı sığırkuyruğu için \%42,9, krizantem için \%69,3 ve biberiye için \%100 olarak saptanmıştır. Uygulamadan 120 saat sonraki sayımlarda ise ölüm oranı sığırkuyruğu uygulaması için \%74,1 iken krizantem uygulamalarında \%100 olarak bulunmuştur.

Anahtar Kelimeler: Beyaz sinek, biberiye uçucu yağı, sığırkuyruğu, krizantem, bitki ekstraktı

\section{Effects of Rosmarinus officinalis Essential Oil and Verbascum cheiranthifo- lium and Chrysanthemum cinerariaefolium Extracts to Greenhouse Whitefly (Trialeurodes vaporariorum)}

\begin{abstract}
In this study, effects of essential oil of rosemary (Rosmarinus officinalis) and plant extracts of mullein (Verbascum cheiranthifolium) and pyrethrin (Chrysanthemum cinerariaefolium) against greenhouse whitefly (Trialeurodes vaporariorum) on tomato plant (Lycopersicon esculentum) has been researched. In the study, 5 different concentrations of essential oils and plant extracts prepared and applied in two different methods as spraying and dipping to tomato plants. After 24 hours counts, maximum mortality rates were $46.3 \%$ for rosemary EO and $0 \%$ for mullein and pyrethrin applicaitons. After 72 hours counts, mortality rates were $42.9 \%$ for mullein, $69.3 \%$ for pyrethrin and $100 \%$ for rosemary applications. After 120 hours counts, mortality rates were $74.1 \%$ for mullein, $100 \%$ for pyrethrin and $100 \%$ for rosemary applications.
\end{abstract}

Keywords: Whitefly, rosemary essential oil, mullein, pyrethrin, plant extract

Basri ŞANLI, https://orcid.org/0000-0003-2872-1427 Arif ŞANLI, https://orcid.org/0000-0002-5443-2082 İsmail KARACA, https://orcid.org/0000-0002-0975-789X 


\section{GíRiş}

Domates dünyada 5.227.883 ha alanda 129.649 .883 ton üretim miktarına sahiptir (Anonymous, 2010). Türkiye üretim miktarı bakımından 11.350 .000 ton ile Çin ve Amerika'dan sonra 3. sırada yer almaktadır (Anonim, 2012). Domatesin ülkemizde çok amaçlı tüketimi ve gıda sanayisinin önemli bir ürünü olması nedeniyle ekim alanları son yıllarda artmıştır. Ancak, üretim sırasında oluşan ürün kayıpları ve bunları önlemek için yapılan mücadele masrafları üretim maliyetini artırmaktadır. Zirai mücadelenin kimyasal mücadele olarak algılandığı ülkemizde, pestisitlerin \%19'u sebze alanlarında kullanılmaktadır (Erkin ve Kişmir, 1996). Bu durum sebzelerde üretim maliyetini artırmanın yanı sıra üründe kalıntı ve benzeri sorunları beraberinde getirmektedir.

Sera beyaz sineği (Trialeurodes vaporariorum Westfood (Hemiptera: Aleyrodidae)), serin bölgelerde seralarda yetiştirilen pek çok bitkide zararlı bir türdür. Sera beyaz sineğine karşı genelde kimyasal savaş uygulanmaktadır. Ancak son yıllarda sentetik insektisitlerin bilinçsizce kullanımı sonucu zararlılarda oluşan dayanıklılık, insan, çevre ve hedef dışı organizmalara olumsuz etkileri bilimsel çalışmalarla kanıtlanmış ve bu zararlı ile savaşta alternatif mücadele yöntemleri arayışına gidilmiştir (Dursun ve ark., 2008).

Bitkiler, zararlılara karşı çok çeşitli morfolojik ve fizyolojik savunma mekanizmasına sahiptir. Bunlar toksin, uzaklaştırıcı, beslenmeyi önleyici, sindirimi zorlaştırıcı gibi doğrudan kimyasal savunma biçimleri ve mum tabakası, pürüzlü yaprak ve dal yüzeyi gibi morfolojik savunma biçimleridir (Smith, 1989). Shanker ve Solanki (2000), bitkiler tarafından salgılanan kimyasal bileşiklerin en önemlilerinin alkaloidler, glikozidler, fenoller, terpenoidler, tanenler ve saponinler olduğunu belirtmiştir. Bu kimyasal bileşikler, zararlılara karşı yüzlerce yıldan beri doğrudan veya dolaylı olarak kullanılmaktadır. Bitkisel kökenli doğal insektisitlerin bir kısmı doğrudan öldürücü olarak kullanılırken, bir kısmı da bu öldürücü etkinin yanında veya ayrı olarak uzaklaştırıcı, beslenmeyi engelleyici vb. yönü ile kullanılmaktadır (Maiteki ve Lamb, 1985; Naqvi ve ark., 1989; Dimetry ve Schmidt, 1992).

Türkiye'de 12000 kadar bitki türünün yetiştiği, bunlardan yaklaşık \% 32'sinin endemik olduğu ve bu türlerden bazılarının uzun yıllardır tıbbi ilaç hammaddesi olarak kullanıldığı belirtilmiştir (Baytop, 1999; Güner ve ark., 2012). Bu kadar fazla tür zenginliğine sahip olan ülkemizde bitki zararlılarına karşı ekstrakt ve uçucu yağların kullanımı önemli bir potansiyel olarak görülmektedir.

Isparta doğal florasında yaygın olarak bulunan Verbascum cheiranthifolium ile Chrysanthemum cinerariaefo- lium ve bölgede yetiştiriciliği yapılan Rosmarinus officinalis'in tarımsal üretimde büyük ölçüde ekonomik zarara neden olan sera beyaz sineği (Trialeurodes vaporariorum)'ne karşı etkilerinin belirlenmesi çalışmanın amacını oluşturmaktadır.

\section{MATERYAL VE YÖNTEM}

Çalışmada, Bitki Koruma Bölümü, Biyolojik Mücadele Araştırma ve Uygulama Laboratuvarına ait iklim odalarında yetiştirilen sera beyaz sineği ile Vilmarine firmasına ait Jadelo ticari isimli baharlık dometes (Lycopersicon esculentum) çeşidi materyal olarak kullanılmıştır. Araştırmada, Ziraat Fakültesine ait Tarımsal Araştırma ve Uygulama Merkezi deneme alanlarında üretimi yapılan biberiye (Rosmarinus officinalis) bitkisinin herba uçucu yağı ile aynı alanda doğal olarak yetişen sığırkuyruğu (Verbascum cheiranthifolium) bitkisinin toprak üstü yeşil aksamı ve Isparta ili Sütçüler ilçesi dağlık alanlarında doğal olarak yetişen krizantem (Chrysanthemum cinerariaefolium) bitkisinin çiçeklerinden elde edilen bitkisel ekstraktlar ve beyaz sinek mücadelesinde yaygın olarak kullanılan \%20 Acetamiprit etkili maddesini içeren kimyasal tarım ilacı uygulama materyali olarak kullanılmıştır. Tablo 2, 4 ve 6'da uçucu yağ ve bitki ekstraktlarının bileşenleri, Şekil 1, 2 ve 3'de ise bu ekstraktlara ait GC-MS Kromotografileri verilmiştir.

\section{Konukçu Bitki Üretimi}

Konukçu bitki olarak kullanılan domates fideleri $25 \mathrm{~cm}$ çapında ve $17 \mathrm{~cm}$ yüksekliğindeki $2,5 \mathrm{~L}$ hacmindeki plastik saksılara şaşırtılarak, iklim odalarında $25 \pm 1{ }^{\circ} \mathrm{C}$ sıcaklık, \%65 \pm 5 nispi nem ve 16:8 saat aydınlık/karanlık ışıklandırma koşullarında gelişmeye bırakılmıştır. Bitkiler 6-7 yapraklı döneme gelinceye kadar bu odalarda muhafaza edilmiş ve daha sonra uygulama yapılmak üzere sera ortamına alınmıştır (Dursun ve ark., 2008).

\section{Sığırkuyruğu (Verbascum cheiranthifolium) Ekstrak- tının Hazırlanması}

Çalışmada kullanılan sığırkuyruğu (Verbascum cheiranthifolium) bitkisi Tarımsal Araştırma ve Uygulama Merkezi deneme alanlarından Ağustos-Eylül aylarında tohum olgunlaşma döneminde toplanmıştır. Toplanan bitkilerin tohum içeren çiçek kısımları ayrılarak gölge koşullarında oda sıcaklığında $\left(23-24^{\circ} \mathrm{C}\right)$ kurutulmuştur. Kurutulan çiçek kısımları (yaklaşık $100 \mathrm{~g}$ ) blender kullanılarak toz haline getirilmiş ve $\% 70$ 'lik etil alkol içerisinde 3 gün süre ile bekletilmiştir. Bu süre içerisinde örnekler çalkalayıcıda sürekli olarak karıştııılmış ve sonunda 0.1 $\mathrm{mm}$ Whatman filtre kağıdından süzülerek sıvı ekstraksiyon elde edilmiştir. Elde edilen ekstre cam tüplere konularak rotary evaporator ile maksimum $45^{\circ} \mathrm{C}$ de yaklaşık 30 dakika tutulmuş ve etil alkol uzaklaştırılmıştır. Cam 
tüplerde kalan kuru örnek su ile yıkanarak alınmış, daha sonra $40{ }^{\circ} \mathrm{C}$ 'de 48 saat süre ile su buharlaştırılarak saf haldeki katı ekstre elde edilmiştir. Elde edilen katı saf madde, blender yardımı ile toz haline getirildikten sonra saf su içerisinde çözülerek $\% 1, \% 2, \% 3, \% 4$ ve $\% 5$ 'lik dozlar halinde solüsyonlar hazırlanmış ve çalışmada kullanılıncaya kadar $-20^{\circ} \mathrm{C}$ 'de saklanmıştır (Khoshnoud ve Khayamy, 2008).

\section{Krizantem (Chrysanthemum cinerariaefolium) Ekstraktının Hazırlanması}

Çalışmada kullanılan krizantem (Chrysanthemum cinerariaefolium) bitkisinin çiçek kısımları Isparta ili Sütçüler ilçesinin dağlık alanlarından tam çiçeklenme döneminde toplanmış ve gölge şartlarında oda sıcaklığında (23-24 $\left.{ }^{\circ} \mathrm{C}\right)$ kurutulmuştur. Kurutulan çiçekler blender yardımı ile toz haline getirildikten sonra $50 \mathrm{gr}$ örnek alınarak $100 \mathrm{ml}$ etanol, $100 \mathrm{ml}$ eter ve $100 \mathrm{ml}$ petrol eteri içerisinde 72 saat süre ile karanlık ortamda bekletilmiştir. Belirtilen sürenin sonunda karışım Whatman filtre $(0.1 \mathrm{~mm})$ kağıdı kullanılarak süzülmüş ve çözelti \% $80^{\prime}$ lik metil alkol (20:80 oranında) ile karıştırımış ve karışımda 2 farklı tabaka meydana gelinceye kadar beklenmiştir. Piretrin içeren sarı renkli tabaka diğerinden izole edilerek rotary evaporator yardımı ile konsantre hale getirilmiştir. Elde edilen katı madde saf su ile çözülerek $\% 1, \% 2, \% 3, \% 4$ ve $\% 5$ 'lik dozlar halinde solüsyonlar hazırlanmış ve çaış̧mada kullanılıncaya kadar $-20{ }^{\circ} \mathrm{C}$ sıcaklıkta saklanmıştır (Pavela, 2009).

\section{Biberiye (Rosmarinus officinalis) Uçucu Yağının Hazırlanması ve GC-MS Analizi}

Araştırmada kullanılan biberiye (Rosmarinus officinalis) uçucu yağı, Tarımsal Araştırma ve Uygulama Merkezi deneme alanlarında Haziran ayı içerisinde çiçeklenme başlangıcı döneminde toplanan bitkilerden elde edilmiştir. Toplanan biberiye örnekleri gölge şartlarda oda sıcaklığında kurutulduktan sonra Clevenger tipi hidro-distilasyon cihazında 3 saat süre ile damıtılarak uçucu yağ elde edilmiş ve koyu renkli cam saklama şişelerine konularak $+4{ }^{\circ} \mathrm{C}$ sıcaklıkta karanlık şartlarda saklanmıştır (Marotti ve Piccaglia 1992). Biberiye uçucu yağının bileşenleri SDÜ Deneysel ve Gözlemsel Araştırma ve Uygulama Merkezi'nde bulunan GC/MS (Gas chromatography/Mass spectrometry) cihazında (QP-5050 GC/MS, Quadrapole detektörlü) belirlenmiştir (Stein, 1990). Cihazın çalışma koşulları: Kapiler kolon: CP-Wax 52 CB (50 m x 0,32 mm, 0,25 $\mu \mathrm{m}$ ), Fırın sıcaklık programı: Dakikada $10^{\circ} \mathrm{C}$ artarak $60^{\circ} \mathrm{C}$ 'den $220^{\circ} \mathrm{C}$ 'ye ulaşmış ve 220 ${ }^{\circ} \mathrm{C}$ 'de 10 dakika kadar bekletilmiştir. Toplam koşturma süresi: 60 dakika, Enjektör sıcaklığı: $240{ }^{\circ} \mathrm{C}$, Detektör sıcaklığı: $250^{\circ} \mathrm{C}$, Taşıyıcı gaz: Helyum (20 ml/dak.). Çaış̧mada, biberiye uçucu yağı $1,3,5,7$ ve $9 \mathrm{ml} / \mathrm{L}$ dozlarında kullanılmıştır (Mahmoud ve ark., 2011). İstenilen konsantrasyonların hazırlanması için, uçucu yağ önce düşük miktarda etil alkol $(10 \mathrm{ml})$ içerisinde çözülmüş, daha sonra uçucu yağların su içerisinde homojen karışması için Tween 80 (su hacminin \% 0.1'i kadar) eklenmiştir (El-Maugy, 2009). Elde edilen karışım son hacmi $1000 \mathrm{ml}$ olacak şekilde saf su içerinde çözülerek istenilen uçucu yağ konsantrasyonları hazırlanmıştır.

\section{Denemelerin Kurulması ve Yürütülmesi}

Bitki büyütme kabinlerinde yetiştirilen ve saksılara şaşırtılan konukçu domates bitkilerinin bir kısmı sera beyaz sineği ile bulaşmanın sağlanması amacıyla beyaz sinek yetiştirilen iklim odalarına alınmıştır. Yumurtalar $25^{\circ} \mathrm{C}$ ' de ortalama 6 gün sonunda açılmaya başladıkları için bulaşık bitkiler, $25 \pm 1{ }^{\circ} \mathrm{C}$ sıcaklık, \% $65 \pm 5$ nispi nem ve 16:8 saat (aydınlık: karanlık) ışıklandırma koşullarında 6-7 gün bekletilmiştir. Bulaşma sağlandıktan sonra domates bitkileri uygulamaların yapılacağı sera ortamında bitki geliştirme yataklarına aktarımış ve diğer bitkilere bulaştırma yapılmıştır. Sera koşullarında bitki büyütme yataklarında yürütülen çalışma, Tesadüf Parselleri Deneme Deseninde Faktöriyel Düzene göre 4 tekerrürlü olarak planlanmıştır. Çalışmada sığırkuyruğu ve krizantem ekstraktları ile biberiye uçucu yağının 5 'er farklı dozu ve 2 farklı uygulama yöntemi (püskürtme ve daldırma) olmak üzere iki faktör ele alınmıştır. Hiçbir uygulama yapılmayan bitkiler kontrol olarak değerlendirilmiştir (Taş, 2008). Çalışmada farklı uygulamalara ait her bir tekerrür için 5'er saksı, toplamda ise 128 saksı (( 3 uygulama $\times 5$ doz $\times 2$ uygulama yöntemi) + (kontrol + Acetamiprit) $x 4$ tekerrür)) kullanılmıştır.

Çalışmada tüm saksılara sera beyaz sineği bulaştırıldıktan sonra uygulama yataklarındaki bitkiler incelenmiş ve yeterli bulaşma olduğu gözlenmiştir. Bitkiler üzerindeki erginler ortamdan izole edilerek her saksıda nimf sayımı yapılmıştır.

Püskürtme uygulamalarında, her bitki için hazırlanan farklı konsantrasyonlardaki uçucu yağ ve ekstraktlar 10 $\mathrm{ml} /$ bitki dozunda el spreyleri kullanılarak bitki yapraklarına püskürtülmüştür. Daldırma uygulamaları, domates yapraklarının, hacimleri $1000 \mathrm{ml}$ olacak şekilde farklı dozlarda hazırlanan uçucu yağ ve bitki ekstraktları içerisine 3 saniye süre ile daldırılması şeklinde yapılmıştır. Her iki yöntemde de uygulamalar yapıldıktan 1, 3 ve 5 gün sonra saksılardaki bitkiler üzerinde canlı ve ölü nimf sayımları yapılmıştır.

Uygulamalar sonucunda elde edilen veriler SAS (2001) istatistik paket programında GLM prosedürü kullanılarak standart varyans analizi tekniğinde analiz edilmiş ve ortalamalar arasındaki farklılıklar Tukey çoklu karşılaştırma testine göre belirlenmiştir. 


\section{BULGULAR VE TARTIŞMA}

\section{Sığırkuyruğu Ekstraktı ve Acetamiprit (\%20) Uygulamalarının Sera Beyaz Sineği Ölü Nimf Oranı Üzerine Etkileri}

Farklı konsantrasyonlarda sığırkuyruğu ekstraktı ve Acetamiprit (\%20) uygulamalarından 1,3 ve 5 gün sonra kaydedilen sera beyaz sineği ölü nimf oranları Tablo 1 'de verilmiştir. Sığırkuyruğu ekstraktı uygulamalarından 1 gün sonra yapılan gözlemlerde uygulamaların sera beyazsineği nimfleri üzerinde etki göstermediği belirlenmiştir. Uygulamalardan 3 gün sonra, ortalama ölü nimf oranları daldırma şeklinde yapılan uygulamalarda (\%28.4) püskürtme şekline yapılan uygulamalara (\%26.1) göre daha yüksek olmuştur. Püskürtme ve dal- dırma şeklinde yapılan uygulamalarda 3 . gün sayımlarında \%1'lik konsantrasyonda ölü nimf oranları sırasıyla $\% 13.8$ ve \%18.9 olurken, \%5'lik konsantrasyonlarda bu oranlar \%42.9 ve \%41.8'e yükselmiştir. Sığır kuyruğu ekstraktı uygulamalarının etkinliği uygulamalardan 5 gün sonra daha belirgin olmuş, uygulama dozundaki artışla birlikte ölü nimf oranları da artarak püskürtme şeklinde yapılan uygulamalarda \%54.7'ye daldırma uygulamalarında ise \%74.1'e yükselmiştir. Acetamiprit (\%20) uygulamalarının ölü nimf oranı üzerine etkisi 3. gün sayımlarında (\% 47.6) sığırkuyruğu ekstraktı uygulamalarından daha yüksek olurken, uygulamalardan 5 gün sonra $\% 5$ 'lik konsantrasyonda daldırma şeklinde yapılan uygulamalar Acetamiprit (\%20) ile benzer etkiye sahip olmuştur. Kontrol olarak değerlendirilen saksılarda nimflerin tamamı canlı kalmıştır (Tablo 1).

Tablo 1. Farklı konsantrasyonlarda sığırkuyruğu ekstraktı ve Acetamiprit (\%20) uygulamalarından 1,3 ve 5 gün sonra sera beyaz sineği ölü nimf oranı (\%)

\begin{tabular}{|c|c|c|c|c|c|c|c|c|c|}
\hline \multirow[b]{2}{*}{ Dozlar } & \multicolumn{3}{|c|}{1 gün sonra } & \multicolumn{3}{|c|}{3 gün sonra } & \multicolumn{3}{|c|}{5 gün sonra } \\
\hline & $\begin{array}{l}\text { Püs- } \\
\text { kürtme }\end{array}$ & Daldırma & Ort. & $\begin{array}{l}\text { Püs- } \\
\text { kürtme }\end{array}$ & Daldırma & Ort. & $\begin{array}{l}\text { Püs- } \\
\text { kürtme }\end{array}$ & Daldırma & Ort. \\
\hline$\% 1$ & 0 & 0 & 0 & 13.8 & 18.9 & $16.4 \mathrm{e}$ & 20.6 & 29.0 & $24.8 f$ \\
\hline$\% 2$ & 0 & 0 & 0 & 15.9 & 22.2 & $19.1 \mathrm{e}$ & 35.5 & 42.4 & $39.0 \mathrm{e}$ \\
\hline$\% 3$ & 0 & 0 & 0 & 23.3 & 30.5 & $26.9 \mathrm{~d}$ & 43.9 & 49.6 & $46.7 \mathrm{~d}$ \\
\hline$\% 4$ & 0 & 0 & 0 & 32.2 & 37.8 & $38.5 \mathrm{c}$ & 52.4 & 66.2 & $59.3 \mathrm{c}$ \\
\hline$\% 5$ & 0 & 0 & 0 & 42.9 & 41.8 & $42.4 \mathrm{~b}$ & 54.7 & 74.1 & $64.4 \mathrm{~b}$ \\
\hline Acet. & 0 & 0 & 0 & 47.6 & 47.6 & $47.6 \mathrm{a}$ & 71.0 & 71.0 & $71.0 \mathrm{a}$ \\
\hline Kontrol & 0 & 0 & 0 & 0 & 0 & $0 f$ & 0 & 0 & $0 \mathrm{~g}$ \\
\hline Ort. & 0 & 0 & 0 & $26.1 \mathrm{~B}$ & $28.4 \mathrm{~A}$ & & $39.7 \mathrm{~B}$ & $47.5 \mathrm{~A}$ & \\
\hline
\end{tabular}

Araştırmada kullanılan sığırkuyruğu ekstraktının 58 farklı bileşenden oluştuğu ve ana bileşenlerden bir tanesinin de saponinler olduğu tespit edilmiştir (Tablo 2). Çaıışmada sığırkuyruğu ekstraktının sera beyaz sineği nimfleri üzerine olan etkisinin içerdiği saponinlerden kaynaklandığı düşünülmektedir. Nitekim, Verbascum türlerinden elde edilen saponinlerin farklı organizmalar üzerinde toksik ve zehirleyici etki gösterdiği Türker ve Gürel (2005) tarafından da bildirilmiştir. Verbascum türlerinin tohumlarından elde edilen ekstraktlar protein biyosentezi üzerine kuvvetli bir engelleyici etki göstermektedir (Paszkiewicz-Gadek ve ark., 1990; Küpeli ve ark., 2007). Saponinlerin insektisidal aktiviteleri üzerine yapılan araştırmalarda, bu bileşiklerin bitki zararlısı böceklerde beslenme davranışları, gelişmeyi düzenleme ve doğrudan öldürme olmak üzere 3 farklı şekilde etki gösterdiği bildirilmiştir (Chaieb, 2010). Bu çalışmada elde edilen bulgulara benzer olarak, Uysal ve ark. (2012), Drosophila melanogaster'in gelişim biyolojisi üzerine Verbascum speciosum tohumlarından elde edilen ekstraktların $(2,4,6,8$ ve $10 \mathrm{mg} / 100 \mathrm{~mL} S D B)$ D. melanogater'de $\mathrm{F} 1$ neslinde ölüm oranının önemli ölçüde arttırdığını bildirmişlerdir. Khoshnoud ve ark. (2008), Verbascum speciosum ekstraktının Sitophilus oryzae erginlerinde ölüm oranını önemli ölçüde arttırdığı ve bu artışın doz artışına paralel olarak gerçekleştiğini belirtmişlerdir. Benzer şekilde $V$. cheiranthifolium ekstraktının Sitophilus oryzae ve Tribolium castaneum yumurtalarından çıkan larvalarda ölüm oranını arttırdığı, yumurtlama oranını ise azalttığı belirtilmiştir (Khoshnoud ve ark., 2008). 
Tablo 2. Verbascum cheiranthifolium ekstraktının bileşenleri

\begin{tabular}{|c|c|c|c|c|c|}
\hline No & Oran \% & Bileşen & No & Oran \% & Bileşen \\
\hline 1 & 0.22 & Methyl glycolate & 30 & 1.46 & Eugenol \\
\hline 2 & 0.18 & Isobutyl alcohol & 31 & 0.90 & n-Dodecanol \\
\hline 3 & 0.25 & Dumasin & 32 & 1.43 & o-Hydroxyacetophenone \\
\hline 4 & 0.61 & $\mathrm{RT}: 3.967$ & 33 & 0.32 & tert-Butyl Methyl-3-oxopentanoate \\
\hline 5 & 0.42 & TRIETHYL FORMATE & 34 & 0.71 & Benzene, 1-(bromomethyl)-3-nitro- \\
\hline 6 & 1.20 & Anon & 35 & 0.15 & 2-Methyl-2-thioethyl propionitrile \\
\hline 7 & 2.97 & Alpha Thujene & 36 & 0.22 & Urea (CAS) Urevert \\
\hline 8 & 5.32 & Allyl alcohol & 37 & 11.39 & n-Butyric acid \\
\hline 9 & 0.85 & Ketene & 38 & 0.16 & DL-2,3-Butanediol \\
\hline 10 & 1.01 & $\mathrm{RT}: 5.583$ & 39 & 0.90 & n-Dodecanol \\
\hline 11 & 0.26 & $\mathrm{RT}: 5.658$ & 40 & 0.34 & 3-Methylbutyl nitrite \\
\hline 12 & 0.42 & TRIETHYL FORMATE & 41 & 0.92 & Coniferyl alcohol \\
\hline 13 & 0.10 & 1,3-Difluoroacetone & 42 & 0.21 & $(5 \mathrm{R})-[5-(2) \mathrm{H}(1)]-2-$ pyrrolidinone \\
\hline 14 & 0.27 & 2-.Beta Pinene & 43 & 2.11 & Palmitic acid \\
\hline 15 & 0.57 & Mycrene & 44 & 8.46 & Ethyl palmitate \\
\hline 16 & 1.21 & 2-Methyl-1-butanol & 45 & 1.78 & 6-Dodecenol \\
\hline 17 & 0.55 & Benzyl alcohol & 46 & 5.56 & 9-Hexadecenoic acid (CAS) \\
\hline 18 & 0.24 & 1,4-Dimethyl-4-vinylcyclohexene & 47 & 2.27 & Delta.-(3)-dodecanol \\
\hline 19 & 0.24 & $\mathrm{RT}: 7.617$ & 48 & 0.71 & 2-Hydroxyisobutyricacid-Methylester \\
\hline 20 & 0.26 & 2-Hexyl-2-decenal & 49 & 10.30 & Ethyl linoleate \\
\hline 21 & 0.44 & Guaiacol & 51 & 2.48 & CIS-8,11,14-EICOSATRIENOIC ACID \\
\hline 22 & 0.13 & $\mathrm{RT}: 8.417$ & 52 & 6.93 & ETHYL 9-HEXADECENOATE \\
\hline 23 & 7.93 & Phenethyl alcohol & 53 & 0.68 & 2-Methyl-2-butynol \\
\hline 24 & 0.84 & n-Butyric acid & 54 & 1.61 & Ethyl palmitate \\
\hline 25 & 0.37 & $\mathrm{RT}: 10.792$ & 55 & 0.89 & (6Z,9Z)-Heptadeca-6,9-diene \\
\hline 26 & 0.37 & 3-phenyl-2-propenal & 56 & 2.67 & Oleamide \\
\hline 27 & 1.46 & Alfol 14 & 57 & 0.49 & Ethyl n-heptadecanoate \\
\hline 28 & 3.16 & 2,3-Dihydrobenzofuran & 58 & 0.19 & 2-Nonen-1-ol \\
\hline 29 & 1.20 & 4-vinyl-2-methoxy-phenol & & & \\
\hline
\end{tabular}

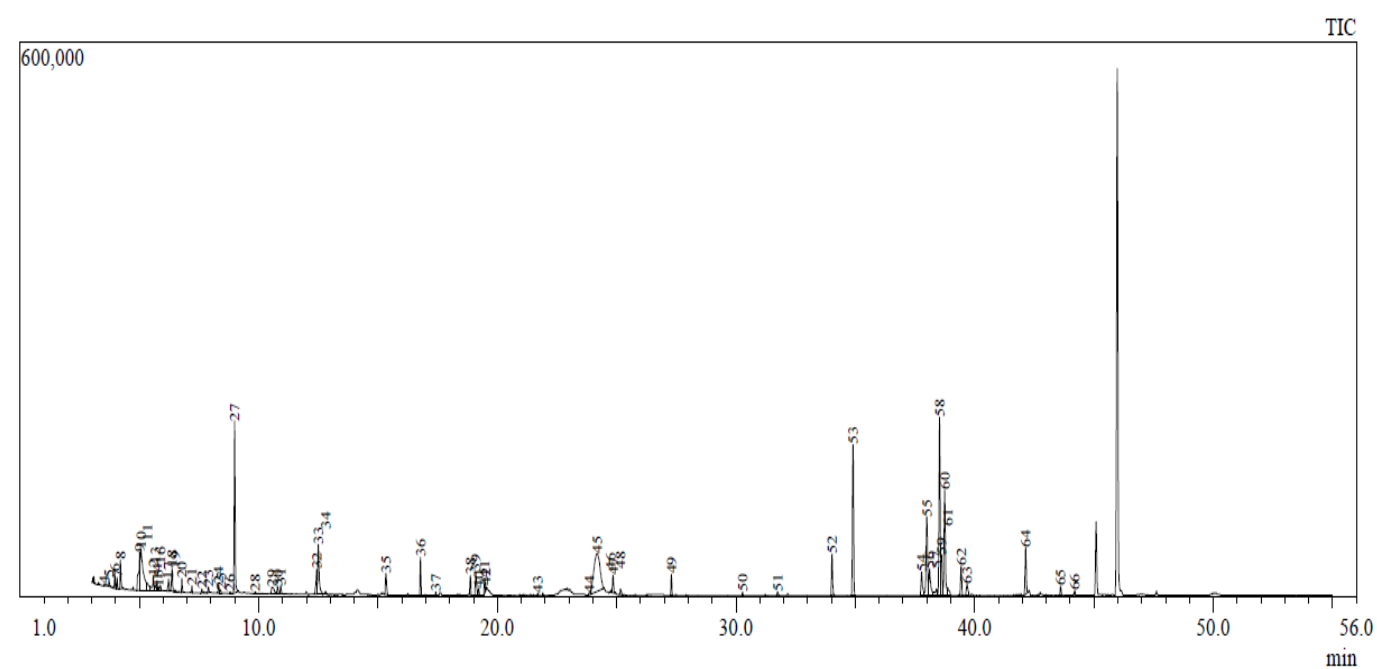

Şekil 1. Verbascum cheiranthifolium'a ait etanol ekstraktının GC-MS Kromotografisi 
Krizantem Ekstraktı ve Acetamiprit (\%20) Uygulamalarının Sera Beyaz Sineği Ölü Nimf Oranı Üzerine Etkileri

Farklı konsantrasyonlarda krizantem ekstraktı ve Acetamiprit (\%20) uygulamalarından 1, 3 ve 5 gün sonra sera beyazsineği ölü nimf oranlarına ilişkin ortalamalar Tablo 3'de verilmiştir. Krizantem ekstraktı ve Acetamiprit (\%20) uygulamalarından 1 gün sonra püskürtme şeklinde yapılan uygulamaların sera beyaz sineği nimfleri üzerine etki göstermediği, daldırma uygulamalarında ise sadece \%5'lik konsantrasyonda krizantem ekstraktının etkili olduğu ve nimflerin \%27.4'ünde ölüm meydana geldiği tespit edilmiştir. Uygulamalardan 3 gün sonra yapılan gözlemlerde, her iki ekstrakt uygulama şeklinin de ölü nimf oranı üzerine etkileri birbirine benzer olmuş ve ortalama ölü nimf oranları püskürtme uygulamalarında $\% 44.0$, daldırma uygulamalarında ise $\% 42.7$ olarak belirlenmiştir. Her iki uygulama yönteminde de \%4'lük konsantrasyona kadar yapılan krizantem ekstraktı uygulamaları sonucu ölü nimf oranları doz artışına paralel olarak artış göstermiş, \%4 ve \%5'lik konsantrasyonlar arasında fark olmadığı gözlemlenmiştir. Krizantem ekstraktının püskürtme şeklinde uygulanması ile 5 . gün sayımlarında ölü nimf oranları \% 4'lük konsantrasyona kadar artarken, daldırma yönteminde \%4'lük ve üzeri konsantrasyonlarda tüm nimflerin öldüğü tespit edilmiştir. Domates fidelerine $\% 3$ ve üzeri konsantrasyonlarda krizantem ekstraktı uygulamaları sera beyazsineği nimflerinde ölüm oranı üzerine Acetamiprit $(\% 20)$ uygulamalarına (\%71.0) göre daha etkili olmuştur (Tablo 3 ).

Tablo 3. Farklı konsantrasyonlarda krizantem ekstraktı ve Acetamiprit (\%20) uygulamalarından 1, 3 ve 5 gün sonra sera beyaz sineği ölü nimf oranları (\%)

\begin{tabular}{cccccccccc}
\hline & \multicolumn{3}{c}{ 1 gün sonra } & \multicolumn{3}{c}{3 gün sonra } & \multicolumn{3}{c}{5 gün sonra } \\
\cline { 2 - 8 } Dozlar & Püskürtme & Daldırma & Ort. & Püskürtme & Daldırma & Ort. & Püskürtme & Daldırma & Ort. \\
\hline \% 1 & 0 & 0 & $0 \mathrm{~b}$ & 20.6 & 21.7 & $21.1 \mathrm{e}$ & 46.0 & 28.1 & $37.0 \mathrm{e}$ \\
$\% 2$ & 0 & 0 & $0 \mathrm{~b}$ & 39.2 & 41.0 & $40.1 \mathrm{~d}$ & 59.3 & 52.9 & $56.1 \mathrm{~d}$ \\
$\% 3$ & 0 & 0 & $0 \mathrm{~b}$ & 62.2 & 61.3 & $61.8 \mathrm{~b}$ & 76.9 & 73.4 & $75.1 \mathrm{~b}$ \\
$\% 4$ & 0 & 0 & $0 \mathrm{~b}$ & 69.3 & 64.7 & $67.0 \mathrm{a}$ & 83.7 & 100.0 & $91.8 \mathrm{a}$ \\
$\% 5$ & 0 & 27.4 & $13.7 \mathrm{a}$ & 69.3 & 62.8 & $66.1 \mathrm{a}$ & 84.4 & 100.0 & $92.2 \mathrm{a}$ \\
Acet. & 0 & 0 & $0 \mathrm{~b}$ & 47.6 & 47.6 & $47.6 \mathrm{c}$ & 71.0 & 71.0 & $71.0 \mathrm{c}$ \\
Kontrol & 0 & 0 & $0 \mathrm{~b}$ & 0 & 0 & $0 f$ & 0 & 0 & $0 \mathrm{f}$ \\
\hline Ort. & $0 \mathrm{~B}$ & $13.7 \mathrm{~A}$ & & $44.0 \mathrm{~A}$ & $42.7 \mathrm{~A}$ & & $60.2 \mathrm{~A}$ & $60.8 \mathrm{~A}$ \\
\hline
\end{tabular}

Krizantem ekstraktının beyaz sinek nimfleri üzerine olan öldürücü etkisinin, çalışmada kullanılan krizantem ekstraktında bulunan Piretrin I ile Cinerin I ve II maddelerinden kaynaklandığı düşünülmektedir. Piretrinler diğer pyrethroid insektisit familyası üyelerinde olduğu gibi böceklerin sinir sistemlerini bozarak ölümlerine neden olmaktadırlar (Aydın ve Mammadov, 2017). Uygun dozda uygulanan piretrin böceklerde kontakt olarak etki göstermekte ve sinir hücrelerinin aşırı uyarılması ile kasların istemsiz olarak sürekli kasılmasına neden olmaktadır. Bunun sonucunda sinir hücrelerinin elektrolit dengesi bozulmakta ve dolayısıyla gerekli uyarı eşiğinin (depolarizasyon) oluşmaması sonucu kasların kasılamayarak felç oluşumuna neden olmakta ve böcekte hızlı bir ölüm gerçekleşmektedir (Casida ve Quistad, Agrawal ve
Sharma, 2010). Konu ile ilgili olarak, 100 ppm dozunda piretrin uygulamasının Trialeurodes vaporiarum erginlerinde \% 95 ve parazitoit Encarsia formosa erginlerinde ise \% 100 ölüme neden olduğu bildirilmiştir (Simmons ve ark., 2002). Aynı çalışmada, 100 ve 500 ppm dozunda piretrin uygulamaları sonucu (nimflerine uygulama) Trialeurodes vaporiorum çıkış oranlarının sırası ile \% 19 ve \% 15'e düştüğü belirtilmiştir. Diğer bir çalışmada, Tanacetum zahlbruckneri (Nab.) Grierson (Asterales:Asteraceae) çiçek ekstraktının (\% 91 ölüm oran) Spodoptera littoralis (Boisduval) (Lepidoptera:Noctuidae) larvaları üzerine kontak toksisite gösterdiği ve \% 91 oranında ölüme neden olduğu bildirilmiştir (Karakoç ve Gökçe, 2012). 
Tablo 4. Chrysanthemum cinerariaefolium extraktının bileşenleri

\begin{tabular}{cclccl}
\hline No & Oran $\%$ & \multicolumn{1}{c}{ Bileşen } & No & Oran \% & \multicolumn{1}{c}{ Bileşen } \\
\hline 1 & 0.15 & n-Undecane & 20 & 0.86 & Oleic acid \\
2 & 4.14 & Ethyl hexanol & 21 & 3.22 & Cinerin I ;2-methyl-4-oxocyclopent- \\
3 & 0.30 & Limonene & 22 & 0.30 & 1-Hexadecyne (CAS) \\
4 & 0.19 & 1-phenyl-2-butene & 23 & 1.88 & Jasmolin I \\
5 & 0.59 & 2-(2-Butoxyethoxy)ethanol & 24 & 0.13 & RT:41.242 \\
6 & 0.21 & Octilin & 25 & 5.22 & Pyrethrin I \\
7 & 0.78 & Isosorbid & 26 & 0.28 & Butacide \\
8 & 0.28 & Trans-chrysanthemal & 27 & 0.13 & RT:42.142 \\
9 & 0.35 & Adacene & 28 & 42.04 & Butacide \\
10 & 0.74 & Beta Farnesene & 29 & 0.21 & Methyl linolelaidate \\
11 & 4.2 & 4-Methyl-2,6-di-tert-butylphenol & 30 & 0.17 & Ttetra Decamethylene glycol \\
12 & 0.17 & RT:24.042 & 31 & 0.38 & Germacrene D \\
13 & 0.22 & Alfol 12 & 32 & 1.97 & (Z)6,(Z)9-Pentadecadien-1-ol \\
14 & 0.28 & 2-CHLORO-5,5-DIMETHYL & 33 & 2.21 & DI-(9-OCTADECENOYL)-GLYCEROL \\
15 & 0.05 & Alfol 14 & 34 & 0.25 & 3,4-Dimethyl-1-decene \\
16 & 1.11 & Palmitic acid & 35 & 2.63 & Cinerin II \\
17 & 0.22 & 1,9-Decadiene & 36 & 2.13 & RT:47.733 \\
18 & 6.18 & Methyl linolelaidate & 37 & 0.39 & 2-BUTYLSPIROPENTANE \\
19 & 14.08 & 9-Hexadecenoic acid (CAS) & 38 & 0.20 & n-Docosane \\
\hline
\end{tabular}

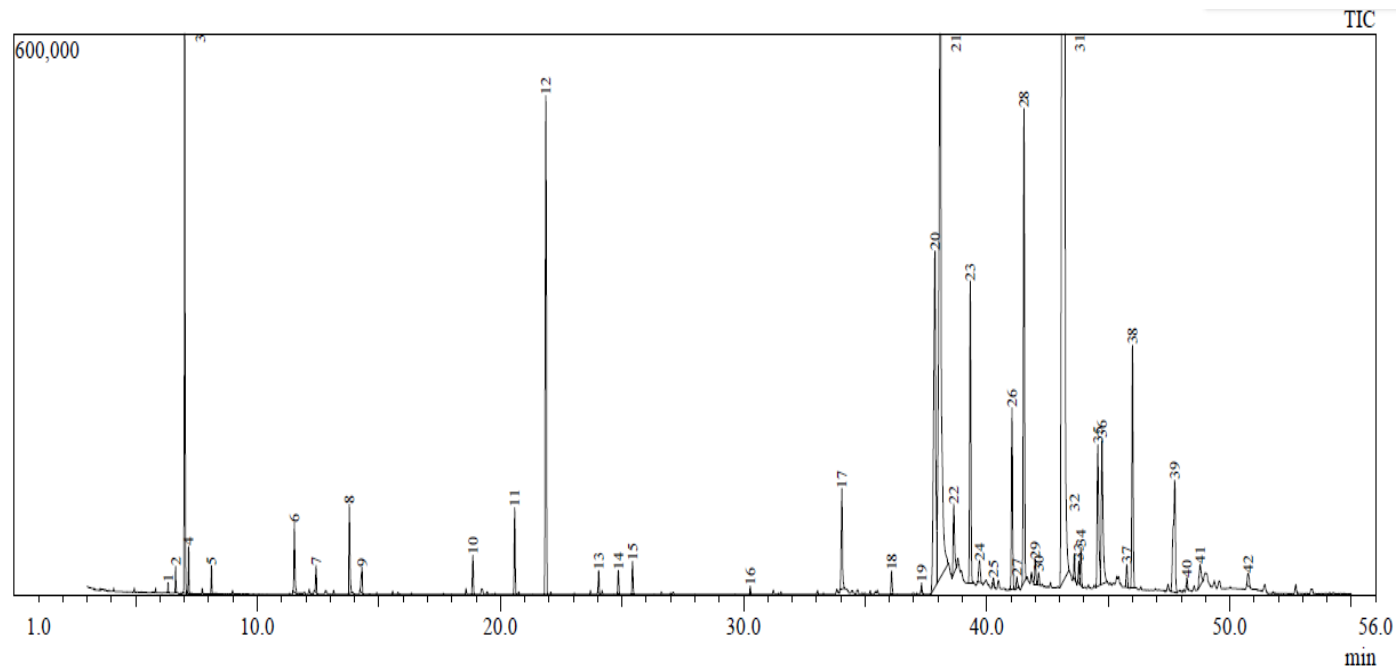

Şekil 2. Chrysanthemum cinerariaefolium'a ait ekstraktın GC-MS Kromotografisi

\section{Biberiye Uçucu Yağı ve Acetamiprit (\%20) Uygulamalarının Sera Beyaz Sineği Ölü Nimf Oranı Üzerine Etkileri}

Değişik dozlarda biberiye uçucu yağı ve Acetamiprit (\%20) uygulamaları sonucu sera beyaz sineğinde 1, 3 ve 5 gün sonra ölü nimf oranlarına ilişkin ortalamalar ve istatistiksel gruplandırmalar Tablo 5'de verilmiştir. Biberiye uçucu yağı uygulamalarında daldırma şeklinde yapılan uygulamalar püskürtme şeklinde yapılanlara göre daha etkili olmuş, uygulamalardan 1,3 ve 5 gün sonra yapılan sayımlarda ölü nimf oranı ortalamaları püskürtme ve daldırma uygulamalarında sırasıyla $\% 2.6$ ve
$\% 21.5, \% 30.6$ ve $\% 57.4, \% 55.0$ ve $\% 71.5$ olarak tespit edilmiştir (Tablo 5). Uygulama dozundaki artışla birlikte her iki uygulama şeklinde de nimf ölüm oranı artmış, daldırma uygulamalarından 3 gün sonra $7 \mathrm{ml}, 5$ gün sonra ise $5 \mathrm{ml}$ ve üzeri dozlarda tüm nimflerin öldüğü, püskürtme uygulamalarında ise uygulamadan 3 gün sonra $9 \mathrm{ml}$ dozunda \% 52.4 olan ölüm oranının 5 gün sonra \% 100'e ulaştığı belirlenmiştir. Uygulamalardan 3 gün sonra yapılan sayımlarda püskürtme şeklinde yapılan uygulamaların Acetamiprit (\%20) ile benzer etki gösterdiği, daldırma uygulamalarında ise $3 \mathrm{ml}$ ve üzeri dozlarda ölü nimf oranının Acetamiprit (\%20) uygulamalarından daha yüksek olduğu saptanmıştır. 5 gün sonra 
yapılan sayımlarda ise püskürtme şeklinde yapılan uygulamalarda $7 \mathrm{ml}$ ve üzeri, daldırma uygulamalarında ise $3 \mathrm{ml}$ ve üzeri dozlar Acetamibrid (\%20) uygulamasından daha etkili olmuştur (Tablo 5).

Tablo 5. Farklı konsantrasyonlarda biberiye uçucu yağı ve Acetamiprit (\%20) uygulamalarından 1, 3 ve 5 gün sonra sera beyaz sineği ölü nimf oranları (\%)

\begin{tabular}{|c|c|c|c|c|c|c|c|c|c|}
\hline \multirow{3}{*}{ Dozlar } & \multicolumn{3}{|c|}{1 gün sonra } & \multicolumn{3}{|c|}{3 gün sonra } & \multicolumn{3}{|c|}{5 gün sonra } \\
\hline & Püs- & Daldırma & Ort. & Püs- & Daldırma & Ort. & Püs- & Daldırma & Ort. \\
\hline & \multicolumn{3}{|c|}{ kürtme } & \multicolumn{3}{|c|}{ kürtme } & \multicolumn{3}{|l|}{ kürtme } \\
\hline $1 \mathrm{ml}$ & 0 & 0 & $0 \mathrm{e}$ & 7.2 & 13.1 & $10.2 \mathrm{e}$ & 13.5 & 39.8 & $26.7 e$ \\
\hline $3 \mathrm{ml}$ & 0 & 27.8 & $13.9 \mathrm{e}$ & 20.6 & 62.3 & $41.4 \mathrm{~d}$ & 51.6 & 89.6 & $70.6 \mathrm{~d}$ \\
\hline $5 \mathrm{ml}$ & 0 & 34.1 & $17.1 \mathrm{c}$ & 38.6 & 78.5 & $58.6 \mathrm{~b}$ & 69.7 & 100.0 & $84.8 \mathrm{c}$ \\
\hline $7 \mathrm{ml}$ & 7.2 & 42.4 & $24.8 b$ & 47.6 & 100.0 & $73.8 \mathrm{a}$ & 79.1 & 100.0 & $89.6 \mathrm{~b}$ \\
\hline $9 \mathrm{ml}$ & 10.9 & 46.3 & $28.6 \mathrm{a}$ & 52.4 & 100.0 & $76.2 \mathrm{a}$ & 100.0 & 100.0 & $100.0 \mathrm{a}$ \\
\hline Acet. & 0 & 0 & $0 \mathrm{e}$ & 47.6 & 47.6 & $47.6 \mathrm{c}$ & 71.0 & 71.0 & $71.0 \mathrm{~d}$ \\
\hline Kontrol & 0 & 0 & $0 \mathrm{e}$ & 0 & 0 & $0 f$ & 0 & 0 & $0 \mathrm{f}$ \\
\hline Ort. & $2.6 \mathrm{~B}$ & $21.5 \mathrm{~A}$ & & $30.6 \mathrm{~B}$ & $57.4 \mathrm{~A}$ & & $55.0 \mathrm{~B}$ & $71.5 \mathrm{~A}$ & \\
\hline
\end{tabular}

Biberiye uçucu yağının sera beyazsineği nimflerine karşı gösterdiği insektisidal etkinin yağda yüksek oranda bulunan camphor ve 1,8 cineol'den kaynaklandığı düşünülmektedir. Biberiye uçucu yağında bulunan farklı bileşenlerin (camphor, $\alpha$-terpinen, $\alpha$-pinen, 1.8 cineol gibi) farklı zararılıar üzerine bireysel olarak farklı derecelerde toksik etki gösterdiği Isman (2008) tarafından da bildirilmiştir. Konu ile ilgili olarak yapılan çalışmalarda, biberiye uçucu yağının böceklere karşı uzaklaştırıcı (Hori, 1998; Amer ve ark., 2001; JiSen ve ErrLieh, 2005), toksik ya da kontak insektisidal (Padin ve ark., 2000; Amer ve ark., 2001; Papachristos ve Stamopoulos, 2002; Isman, 2008) ve yumurtlamayı ve beslenmeyi azaltıcı (Dover, 1985) etki gösterdiği birçok araştırmacı tarafından da bildirilmiştir.
Bu çalışmadaki bulgulara benzer olarak, Yıldırım ve ark. (2011), biberiye uçucu yağının Sitophilus granarius (Coleoptera:Curculionidae) erginlerine karşı etkili olduğunu ve bu etkinin uygulama doz ve uygulamadan sonra geçen zamana bağlı olarak artış gösterdiğini bildirmişlerdir. Araştırmacılar en yüksek ölüm oranının (\%93.9) 20 ml dozunda ve uygulamadan 96 saat sonra gerçekleştiğini belirtmişlerdir. Yapılan diğer bir çalışmada, Dendroctonus micans (Kugelann) (Coleoptera: Curculionidae: Scolytinae)'ın larvalarına karşı 5 ve $10 \mathrm{ml}$ dozlarında biberiye uçucu yağının etkilerini araştırmışlar ve uygulamadan 72 saat sonra ölüm oranının sırası ile $\% 87.3$ ve \%97.3 olduğunu bildirmişlerdir (Göktürk ve ark., 2011). 
Tablo 6. Rosmarinus officinalis uçucu yağının bileşenleri

\begin{tabular}{cclccl}
\hline No & Oran \% & \multicolumn{1}{c}{ Bileşen } & No & Oran \% & \multicolumn{1}{c}{ Bileşen } \\
\hline 1 & 7.09 & Alpha pinene & 18 & 1.21 & 3-(Trans Isopinocampheny) \\
2 & 6.11 & Camphene & 19 & 0.24 & Endo Formyl-ExomethyleNobornane \\
3 & 0.87 & 1-Octen-5-OL & 20 & 6.53 & Endo-Borneol \\
4 & 1.62 & Beta Pinene & 21 & 0.21 & n-Nonyl alcohol \\
5 & 6.83 & Beta Myrcene & 22 & 2.07 & Terpineol \\
6 & 0.75 & Phellandrene & 23 & 3.88 & Linalyl propionate \\
7 & 1.47 & Beta Ocimene & 24 & 3.48 & Verbenone \\
8 & 1.19 & Alpha Terpinene & 25 & 0.30 & RT:8.667 \\
9 & 1.42 & p-Cymene & 26 & 0.12 & Cyclopropane, nonyl- (CAS) \\
10 & 15.25 & 1,8-Cineole & 27 & 0.34 & Beta Citronellol \\
11 & 1.29 & Gamma Terpinene & 28 & 0.51 & Cis-Myrtanol \\
12 & 1.38 & o-Mentha-2(8),3-diene & 29 & 0.20 & Trans-Geraniol \\
13 & 0.45 & Filifolone & 30 & 3.65 & Endobornyl Acetate \\
14 & 4.54 & Linalool & 31 & 0.66 & Carvacrol \\
15 & 21.54 & Camphor & 32 & 1.61 & Trans-Caryophyllene \\
16 & 0.55 & Verbenol & 33 & 0.36 & Alpha Humulene \\
17 & 0.20 & exo-methyl-camphenilol & 34 & 0.20 & Beta Bisabolene \\
\hline & & & & & \\
\hline
\end{tabular}

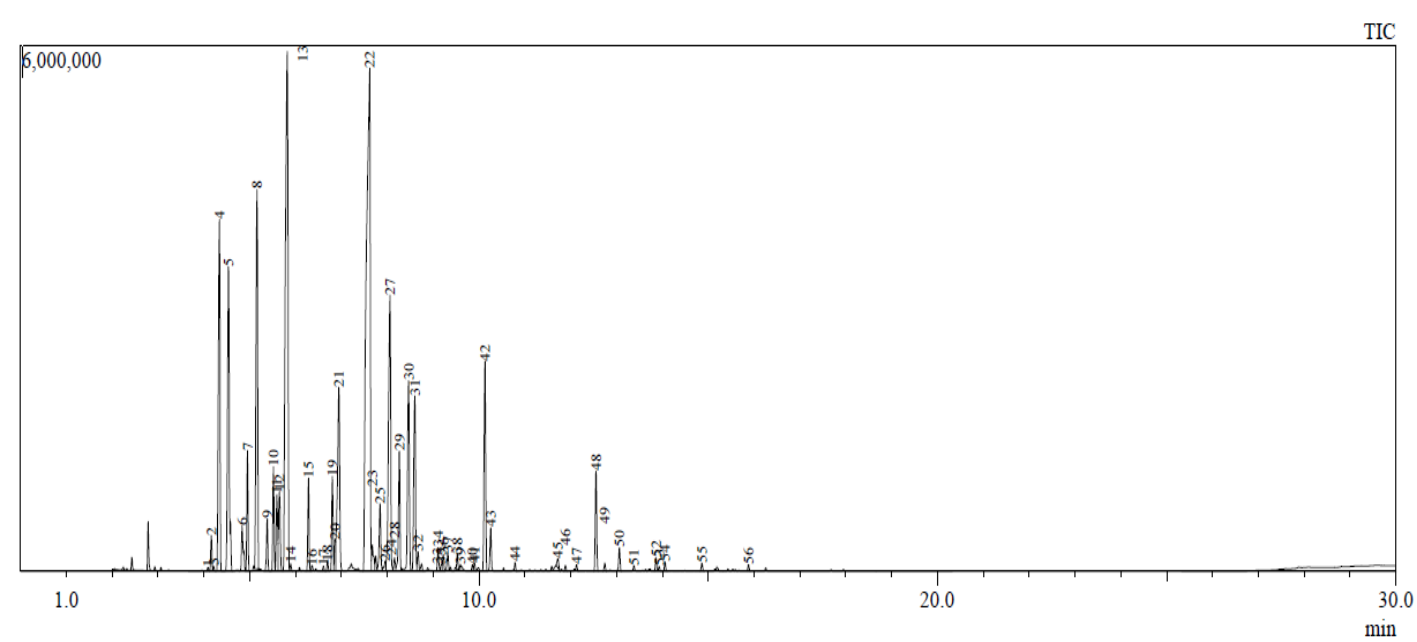

Şekil 3. Rosmarinus officinalis uçucu yağına ait GC-MS Kromotografisi

\section{SONUÇ VE ÖNERILER}

Çalışmada sığırkuyruğu ekstraktının sera beyazsineği nimfleri üzerine orta dereceli etki gösterdiği, uygulamalardan 1 gün sonra herhangi bir etki görülmezken, 3 gün sonra niflerin yaklaşık \%40'nın, 5 gün sonra ise $\% 70$ 'inin öldüğü saptanmıştır. Krizantem ekstraktı uygulamalarının sera beyazsineği nimflerine etkisi sığırkuyruğundan daha yüksek olmuş, uygulamalardan 3 gün sonra her iki uygulama şeklinde de nimflerin \% 60'ından fazlası, 5 gün sonra ise \%80'den fazlası ölmüştür. Sera beyazsineği nimfleri üzerine en kuvvetli etkiyi biberiye uçucu yağı göstermiştir. Biberiye uçucu yağının nimfler üzerine etkisi uygulamalardan hemen sonra görülmeye başlamış, ilk gün sayımlarında yüksek dozlarda nimflerin \% 46.3'ünün öldüğü saptanmıştır. Daldırma şeklinde yapılan uçucu yağ uygulamaları sprey şeklinde yapılana göre daha yüksek etki göstermiş ve uygulamalardan 3 gün sonra $7 \mathrm{ml}$ ve üzeri dozlarda tüm nimflerin öldüğü gözlenmiştir. Uygulamalardan 5 gün sonra yapılan sayımlarda ise sprey şeklinde $9 \mathrm{ml}$, daldırma şeklinde ise $5 \mathrm{ml}$ ve üzeri dozlarda nimflerin tamamının öldüğü belirlenmiştir. Acetamiprid (\%20) uygulamalarında ise ölü nimf oranları uygulamadan 3 gün sonra $\% 47.6,5$ gün 
sonra ise \%71.0 olarak belirlenmiştir. Yüksek dozda (\%5) yapılan sığırkuyruğu ekstraktı uygulamaları Acetamiprid (\%20) ile benzer etki gösterirken, \% 3 ve üzeri konsantrasyonlarda krizantem ekstraktı uygulamaları ile $3 \mathrm{ml}$ ve üzeri dozlarda daldırma şeklinde uygulanan biberiye uçucu yağı Acetamiprid (\%20)'den daha kuvvetli aktivite göstermişlerdir. Uçucu yağ ve bitki ekstraktlarının sera beyazsineği nimflerine etkileri genellikle uygulama dozuna bağlı olmuş ve yüksek dozlarda etkinlikleri artmıştır. Krizantem ekstraktı uygulamalarında uygulama yönteminin nimf ölüm oranına önemli bir etkisi olmazken, diğer uygulamalarda daldırma uygulamalarının daha etkili olduğu anlaşılmıştır.

Alternatif mücadele yöntemleri içerisinde bitkilerden elde edilen ekstraktlar ve uçucu yağlar zararlılarla mücadelede önemli bir yer tutmaktadır. Bitkilerden elde edilen ekstraktların zararlılara karşı toksik, uzaklaştırıcı (repellent), beslenmeyi engelleyici (antifeedant), gelişme ve çoğalmayı engelleyici etkiler gösterdiği yapılan bir çok çalışma ile ortaya konmuştur (Mwangi ve ark., 1992; Schmitt, 1994; Ndungu ve ark., 1995; Kamaraj ve ark. 2011; Miresmailli ve Isman, 2014; Pavela, 2014; Khan ve ark. 2017). Tarımsal üretimde kullanım potansiyeline sahip bitkisel kökenli preperatların hem hedef dışı organizmalar hem de çevresel etkileri bakımından olumsuz etki gösterme olasılıklarının düşük olacağı tahmin edilmektedir.

Araştırmada kullanılan bitkisel kökenli uçucu yağ ve ekstraktların insan, bitki ve hayvan sağlığı ile birlikte çevre ile ilgili gelecek nesillere daha sağlıklı ürünlerin tüketimine dayalı bir bakış açısı yakalanabilmesi için ümit var olduğu görülmektedir. Çalışmada ele alınan biberiye uçucu yağı ile sığırkuyruğu ve krizantem ekstraktlarının sera beyazsineği nimlerinin mücadelesinde Acetamibrit (\%20)'e alternatif olarak kullanım potansiyeline sahip oldukları anlaşılmıştır. Bununla birlikte, araştırma konu olan uçucu yağ ve ekstraktların hedef dışı organizmalar ile çevreye olan etkilerinin geniş üretim alanlarında tekrar denenerek araştırılması gerektiği sonucuna varılmıştı.

\section{KAYNAKLAR}

Amer, S. A. A., Refaat, A. M., Momen, F. M. (2001). Repellent and oviposition-deterring activity of rosemary and sweet marjoram on the spider mites Tetranychus urticae and Eutetranychus orientalis (Acari: Tetranychidae). Acta Phytopathol. Entomol. Hung. 36: 155-164.

Agrawal, A., Sharma, B. (2010). Pesticides induced oxidative stress in mammalian systems. Int. J. Biol. Med. Res., 1(3): 90-104.

Anonymous (2010). Türkiye İstatistik Kurumu (Web sayfası: http://www.tuik.gov.tr). (Erişim tarihi: 12.12.2010).

Anonim (2012). http://tr.wikipedia.org/ (Erişim tarihi: 12.12.2012).
Aydın, Ç., Mammadov, R. 2012. İnsektisit Aktivite Gösteren Bitkisel Sekonder Metabolitler ve Etki Mekanizması. Marmara Pharmaceutical Journal 21: 30-37.

Baytop, T. (1999). Therapy with Medicinal Plants in Turkey (Past and Present), Nobel Tıp Kitabevleri Ltd., İstanbul, pp. 334.

Casida, J.E., 1980. 'Pyrethrum Flowers and Pyrethroid Insecticides.' Environmental Health Perspectives. 34, 189-202.

Chaieb, I. (2010). Saponins as insecticides: a review. Tunisian Journal of Plant Protection 5: 39-50.

Dimetry, N., Schmidt, G.H. (1992). Efficacy of Neem-Azal-S and Margozan-O against the bean aphid, Aphis fabae. Anz Schadl Pflanz Umw, 65: 75-79.

Dover, J. W. (1985). The responses of some Lepidoptera to Labiatae herb and white clover extracts. Entomol. Exp. Appl. 39: 177-182.

Dursun, O., Taç, G., Eskin, A., Yörük, B., Serçebay, U., Sarı, S. (2008). Trialeurodes vaporariorum WESTFOOD (Hom.: Aleyrodidae) Üzerinde Bazı Böcek Gelişim Düzenleyicilerin (IGR) Etkisi. Adnan Menderes Üniversitesi Ziraat Fakültesi Dergisi, 5(2): 25-32.

El-Mougy, N.S. (2009). Effect of Some Essential Oils For Limiting Early Blight (Alternaria Solani) Development In Potato Field. Journal of Plant Protection Research, 49(1): 57-62.

Erkin, E. ve Kişmir, A. (1996). Dünyada ve Türkiye'de Tarım İlacı Kullanımı. II. Uluslararası Tarım İlacı Sempozyumu Raporları, Ankara, 18-21

Göktürk, T., Kordali, S., Calmasur, O. and Tozlu, G. (2011). Insecticidal Effects Of Essential Plant Oils Agaınst Larvae Of Great Spruce Bark Beetle, Dendroctonus Micans (Kugelann) (Coleoptera: Curculıonidae: Scolytinae). Fresenius Environmental Bulletin, 20 (9a): 2365-2370.

Güner, A., Aslan, S., Ekim, T., Vural, M., Babaç, M.T., 2012. Türkiye Bitkileri Listesi (Damarlı Bitkiler). Nezahat Gökyiğit Botanik Bahçesi ve Flora Araştırmaları Derneği Yayını, İstanbul.

Hori, M. (1998). Repellency of rosemary oil against Myzus persicae in a laboratory and in a screenhouse. Journal Chemical Ecology, 24: 1425-1432.

Isman, M.B. (2008). Botanical insecticides: for richer, for poor. Pest Managemet Science 64: 8-11.

JiSen, H., ErrLieh, H. (2005). The repellent effect of several repellent plants on the mosquito and house fly. Formos. Entomology, 25: 221-230.

Kamaraj, C., Rahuman, A. A., Bagavan, A., Elango, G., Zahir, A. A., \& Santhoshkumar, T. (2011). Larvicidal and repellent activity of medicinal plant extracts from Eastern Ghats of South India against malaria and filariasis vectors. Asian Pacific Journal of Tropical Biomedicine, 4, 698-705.

Karakoç, Ö.C., Gökçe, A., 2012. Contact toxicities of plant extracts to Spodoptera littoralis (Lepidoptera: Noctuidae). Türk. entomol. derg., 36 (3), 423-431.

Khan, S., Taning, C.N.T., Bonneure, E., Mangelinckx, S., Smagghe, G., Shah, M.M. 2017. Insecticidal activity of plant-derived extracts against different economically important pest insects. Phytoparasitica DOI 10.1007/s12600017-0569-y.

Khoshnoud, H., Nemati, N., Amimia, R., Ghourttapeh, A.H., Tajbakhsh, M., Talati, F., Salehzadeh, H. (2008). Insecticidal Properties of Verbascum cheiranthifolium Against $R$. dominica on Wheat and Barley. Pakistan Journol of Biological Science, 11(5):783-787. 
Khoshnoud H, ve Khayamy, M. (2008). Insecticidal Effects of Ethanolic Extract from Verbascum cheiranthifolium Boiss. Against Two Stored-Product Insect Pests Species. Journal of Biological Sciences, 8: 191-195.

Kupeli, E., Tatli, I.I., Akdemir, Z.S., Yeşilada, E. (2007). Bioassay-guided isolation of anti-inflammatory and antinociceptive glycoterpenoids from the flowers of Verbascum lasianthum Boiss. Ex Bentham. Journal Ethnopharmacol, 110: 444-450.

Mahmoudvand, M., Abbasipour, H., Basij, M., Hosseinpour, M.H., Rastegar, F., Nasiri, M.B. (2011). Fumigant Toxicity Of Some Essential Oils On Adults Of Some Stored-Product Pests. Chilean Journal of Agricultural Research, 71(1):8389.

Maiteki, G.A. ve Lamb, B.J. (1985). Spray timing and economic Threshold for pea aphid Acyrthosiphon pisum on field peas in Manitoba. Journal Economic Entomology, 78: 14491454.

Marotti, M., Piccaglia, R. (1992). The Influence of Distillation Conditions on the Essential OilComposition of Three Varietiesof Foeniculum vulgare Mill. Journal of Essential Oil Research, 4(6): 569-576.

Miresmailli, S., \& Isman, M. B. (2014). Botanical insecticides inspired by plant-herbivore chemical interactions. Trends in Plant Science, 19, 29-35.

Mwangi, J. W., Addae, M., I., Muriuki, G., Munavu, R., Lwande, W. and Hassanalı, A. (1992). Essential oils of Lippia Species in Kenya IV: Maize Weevil (Sitophilus zeamais) Repellency and Larvicidal Activity. Int. Pharmacognosy, 30(1): 916.

Naqvi, S.N., Nuralain, S.M., Azmi, M.A. ve Asdaque, T. (1989). Effect of Neem fraction and Malathion against whiteflies, Aleurobus barodensis on Brinijal crop (Solanum melanogena). Sarhad Journal Agriculture, 5: 25-28.

Ndungu, M., Lwande, W., Hassanali, A., Moreka, I. and Chabra, S.C. (1995). Cleome Monophylla Essential Oil and its Constituentsas Tick (Rhipicephalus appendiculatus) and Maize Weevil (Sitophilus zeamais) Repellents. Ent. Exp. Et Appl., 76: 217-222.

Padin, S., Ringuelet, J. A., Bello, D., Cerimele, E. L., Re, M. S., Henning, C. P. (2000). Toxicology and repellent activity of essential oils on Sitophilus oryzae L. And Tribolium castaneum Herbst. J. Herbs, Spices ve Med. Plants, 7: 67-73.

Papachristos, D.P. ve Stamopoulos, D.C. (2002). Repellent, toxic and reproduction inhibitory effects of essential oil vapours on Acanthoscelides obtectus (Say) (Coleoptera: Bruchidae). J. of Stored Products Research, 38(2): 117128.
Paszkiewicz-Gadek, A., Grochowska, K., Galasinski, W. (1990). Effect of the aqueous extract and saponin fraction from the flowers of Verbascum thapsiforme on protein biosynthesis in a rat liver ribosomal system. Phytother Research, 4 (5): 177-181.

Pavela, R. (2009). Effectiveness of some botanical insecticides against Spodoptera littoralis Boisduval (Lepidoptera: Noctudiae), Myzus persicae Sulzer (Hemiptera: Aphididae) and Tetranychus urticae Koch (Acari: Tetranychidae). Plant Protection Science, 45(4): 161-167.

Pavela, R. (2014). Insecticidal properties of Pimpinella anisum essential oils against the Culex quinquefasciatus and the nontarget organism Daphnia magna. Journal of Asia Pacific Entomology, 17, 287-293.

Schmitt, A. (1994). Plant Extracts as Pest and Disease Control Agents. Proceedings of the international meeting, 2-3 June 1994, Trento, 264-272.

Shanker, C. ve Solanki, K.R. (2000). Botanical insecticides: A historical perspective. India, Asian Agrihistory 4(2): 21-30.

Simmons, M.S.J., Manlove, J.D., Blaney, W.M. ve Khambay, B.P.S., (2002). Effects ofselected botanical insecticides on the behaviour and mortality of glasshousewhitefly Trialeurodes vaporiarum and the parasitoid Encarsia formosa. Entomologia Experimentalis et Applicata, 102, 3947.

Smith, C. M. (1989). Plant resistance to insects- A fundamental approach. pp 286.John Wiley ve Sons, Inc. Canada.

Stein S.E. (1990). National Institute of Standards and Technology (NIST). Mass Spectral Data Base and Software, Ver. 3.02. Gaithersburg, Maryland, USA.

Taş, T. (2008). Pamukta Kullanılan Bazı Pestisitlerin Beyazsinek Parazitoidi Eretmocerus mundus MERCET (Hymenoptera: Aphelinidae)'a Olan Etkilerinin Laboratuvar Koşullarında Belirlenmesi. Çukurova Üniversitesi Fen Bilimleri Enstitüsü, Yüksek Lisans Tezi, Adana, $40 \mathrm{~s}$.

Türker, A.U., Gürel E. (2005). Common mullein (Verbascum thapsus L.): recent advances in research. Phytother Research, 19(9): 733-739.

Uysal, H., Aksakal, Ö., Aşkın, H. (2012). Developmental disorders caused by Verbascum speciosum Schrad. Extracts in Drosophila melanogaster (Diptera: Drosophilidae). Mehmet Akif Ersoy Üniversitesi Fen Bilimleri Enstitüsü Dergisi, 3(2): 7-11.

Yıldırım, E., Kordalı, S., Yazıcı, G. (2011). Insecticidal Effects of Essential Oils of Eleven Plant Species From Lamiaceaeon (Sitophilus granarius L.) (Coleoptera: Curculionidae). Romanian Biotechnological Letters. 